\title{
Erratum to: Neuronal Glutathione Content and Antioxidant Capacity can be Normalized In Situ by N-acetyl Cysteine Concentrations Attained in Human Cerebrospinal Fluid
}

\author{
Reno C. Reyes ${ }^{1,2}$ • Giordano Fabricio Cittolin-Santos ${ }^{1,2,3,4}$ • Ji-Eun Kim ${ }^{1,2}$. \\ Seok Joon Won ${ }^{1,2}$ - Angela M. Brennan-Minnella ${ }^{1,2}$ - Maya Katz ${ }^{1,2}$. \\ Graham A. Glass $^{1,2} \cdot$ Raymond A. Swanson ${ }^{1,2}$
}

Published online: 9 December 2015

(C) The American Society for Experimental NeuroTherapeutics, Inc. 2015

\section{Erratum to: Neurotherapeutics}

DOI 10.1007/s13311-015-0404-4

Due to errors introduced during the production process, nitrous oxide was replaced with nitric oxide in two locations in the Materials and Methods section of the original publication of this article. The article has been updated to reflect the author's original use of nitrous oxide. Springer apologizes for this error.

The online version of the original article can be found at http://dx.doi.org/ 10.1007/s13311-015-0404-4.

\footnotetext{
Raymond A. Swanson

raymond.swanson@ucsf.edu

1 Neurology Service, San Francisco Veterans Affairs Medical Center, 4150 Clement St., San Francisco, CA 94121, USA

2 The Department of Neurology, University of California, San Francisco Medical Center, San Francisco, CA, USA

3 Programa de Pós Graduação em Ciências Biológicas: Bioquímica, UFRGS, Porto Alegre, Brazil

4 Science Without Borders, CNPq, Brasilia, Brazil
} 